\title{
The Influence Factors of Ternate Language Shift in Ternate City
}

\author{
Farida Maricar \\ Khairun University, Faculty of Letters and Culture, Ternate, North Maluku, Indonesia
}

\begin{abstract}
The shift of language occurs when the mother tongue began to be abandoned by the native speakers and collectively to use another language. There are external and internal factors cause a shift in a language, i.e. cultural factors, economics, history, marriage patterns, locality, sustainability and inter-generational transfer. In addition to external factors, sociolinguistic and internal factors such as motivation, language behavior, language attitudes and language skills also contribute to language shift of Ternate. Results of the research shows that the job variable has the highest influence towards TTL shift is $59.32 \%$, and then followed by bilingual, $44.10 \%$. Attitude is $\mathbf{4 0 . 8 6 \%}$ and level of education, $\mathbf{4 0 . 0 7 \%}$. Meanwhile cultural variable does not significantly effects the shift of TTL.
\end{abstract}

Keywords: Ternate language, language shift, internal and external factors

\section{Introduction}

Language is one of valuable cultural heritages which covers spiritual, mental, feeling, and customs of its speakers (Alwasilah, 2007). According to Wijana and Muhammad (2006), language represents the speakers' uniqueness in expressing their experience and their world view. In addition, language also expresses its speakers' personality and intellectuality. Both personality and intellectuality will enable them to respect their language and keep using the language properly. However, language tends to change regularly; therefore, it needs the speakers attitude in using the language. Language attitude holds an important role in determining a language's vitality. The more the speakers are loyal to use their language, the more the language will alive, and vice versa. On the other hand, the weakness of language maintenance will cause to the language shift as well as language endangered.

Mackey (1973) stated that there are a numbers of indicators in measuring a strength of the language, i.e. demographic, language spread, economy, ideology, and culture. These indicators will influence the speakers of the language to switch to other languages in their communication. Switching the code from one language (mother tongue, L1) to the other languages (L2, L3) in communication is called shifting language. One of the reasons of shifting from native language (mother language, L1) to a new language (L2, L3) is a negative view the speakers of a native language. Generally the native speakers of L1 suspect that their native language is an old fashioned language, non prestige, and causes difficulties in their jobs. In Indonesia, Poedjosoedarmo (2003) explained a fact about the relationship between national (official) language and native language. National language (Indonesian) gets more established, enrich, standardize, more efficient and consistent; on the other hand, native languages become non established, poor, non standardize, no more efficient and consistent.

Other reasons states that generally new generation are not interested to use their native language; they tend to pay their attention to instrumental functions of language, specifically on economic and prosperity benefits. They do not realize the function of language as a medium to understand ethic and aesthetic values covered in the language, which in turn will support local wisdom of a community. Said (2010) argued that every ethnicity has their own valuable folklores, customs, and traditions which only can be understood well through the use of mother tongue since they represent local symbols.

In Ternate, the native language (Ternate language, henceforth TEL) is present among the speakers of TernateMalay language, henceforth TML), National/Official language (Bahasa Indonesia, henceforth INL), and other local languages, minority languages. This condition threatens the speakers of TTL to keep maintaining their language. The positive attitude towards TTL will prolong the live-span of the language; on the other hand, negative attitude towards TTL will cause its speakers to shift to other languages, TML or INL.

Due to this phenomenon, the researcher hypothesizes that TTL has been influenced by TML or INL. Therefore, this paper is focused to analyze the factors cause language shift from TTL to TML or INL.

\section{Literature Review}

\subsection{Ternate and its Language}

Ternate is a small island with total population 207.789 (male 105.597 and female 102.192) (BPS Kota Ternate, 2014). The land area of Ternate is $250.85 \mathrm{kms} 2$, it is covered by $5.547,55 \mathrm{kms} 2$ of the sea. Astronomically, Ternate lies between $0 \mathrm{o}-2 \mathrm{o}$ of northern latitude and between $260-128 \mathrm{o}$ of eastern longitude; and geographically, it surrounded with Maluku Sea to the northern, southern, and western, and with Halmahera strait to the eastern.

Previously, Ternate was governed by the Sultanate; but nowadays it is ruled by a major. Ternate has seven districts: District of Ternate Utara, Ternate Tengah, Ternate Selatan, Pulau Ternate, Pulau Hiri, and Pulau Batang Dua. Despite Ternate is a small island city, it is known as multiethnic and multilingual city, since its population come from different ethnics with different languages. 


\section{International Journal of Science and Research (IJSR) \\ ISSN (Online): 2319-7064}

Index Copernicus Value (2013): 6.14 | Impact Factor (2014): 5.611

TTL as one of the native languages in Indonesia, especially for ethnic group of Ternate in the province of North Maluku functions as the symbol of regional pride and identity for its speakers. According to Grimes (2002) the number of speakers of Ternate was 42,000 people.

TTL is used as a first language, at the same it is also used by the Sultanate of Ternate in traditional ceremonies. In addition, TTL is not only used in Ternate region, it is also used in some regions under the authority of the Sultanate, namely in the West, North, and South Halmahera region as a lingua-franca.

Masinambow (2001) says that TTL had taken a role as the lingua franca besides the TML, and acted as a medium of communication among ethno-linguistic groups that live in the socio-political system of the sultanate of Ternate. Referring to its role, TTL was called as language of kolano 'language of the king' (Ibrahim, 2009). Additionally, Litamahuputty (2012) mentions that TTL is the first language for most people who live in rural areas, often referred to the 'blakang gunung' (literally 'behind the mountain') in the intra-ethnic association.

TTL as a regional language in North Maluku also experienced intermingling with INL. As a result of the intermingling produces INL dialect of Ternate, the TML or Maluku Utara Malay (North Moluccan Malay (Voorhoeve, 1983; Taylor, 1983; Bowden, 2005). Masinambow (1976) called this language as Halmahera Malay. This language also often referred to as market Malay (bazaar Malay). TML is used daily in the realm of public sphere and of the family to distinguish with formal and official variety of INL.

TML is spoken by the majority of the population in North Maluku province as inter-ethnic language. The development of this variant is influenced by locals variants, so it shows difference typical between other Malay variants both in eastern and western Indonesia. The vocabulary of TML mostly comes from TTL and also from adjusted INL.

In terms of vocabulary, both TTL and TML are also strongly influenced by Malay, Portuguese, Dutch, Arabic and Chinese, because of the contact between the languages since pre-colonial period and afterward.

In addition, many vocabularies in TTL lost in communication and replaced with INL ones. For example, many teenagers and even adults have replaced the word 'guae' with 'mangga' in their everyday communication. Here are examples of some of the differences in vocabulary in TTL, TML and INL:

Table 1: The Vocabulary Differences in TTL, TML and INL

\begin{tabular}{|c|c|c|}
\hline TTL & TML & INL \\
\hline ake & aer & air \\
\hline ua & tara $($ da $)$ & tidak \\
\hline kololi & ron & keliling \\
\hline cabu: & sacubi & sedikit \\
\hline ngona & ngana & kamu \\
\hline guae & mangga & mangga \\
\hline
\end{tabular}

\subsection{Language Attitude}

Language is a mental attitude or feelings towards the position of one's own language towards others (Kridalaksana, 2008). Since attitude is abstract, it can only be seen through behavior. However, various researches show that what appears in the behavior does not necessarily indicate an attitude. Likewise, a person's attitude is not always reflected in his behavior.

Garvin and Mathiot (1968, cf. Fishman, 1972) formulated the three characteristic of language attitude which indicates positive attitude toward language, namely:

a. Language allegiance (language loyalty) that encourage people to keep maintaining their language, and preventing from the influence of other languages.

b. Language pride that encourage people to develop the language and use it as a symbol of identity and unity of the community.

c. Language awareness that encourages people to use language carefully and politely. This is a huge factor influence language use.

Factors that lead to language preservation and language shift in a speech community are varies between one region with others. Grosjean (1982) classify these factors into five factors, namely social, attitude, language usage, government policy, and other factors.

Similar factors introduced by Holmes (1994) that the factors which encourage language shift are factors of economic, social, politic, demographics, behaviors, and values in a community.

Gurnawan (1993) also stated that shift in a language is caused by a number of factors, such as sociolinguistic factors, psychological, demographic, and economic. Sociolinguistic factor in this case is bilingualism, followed by leakeage of diglossia. Therefore, it is easy to shift the language when it bears a low functionality. In addition to the bilingualism, speakers or demographic factors are also a considerable factor affect the durability of a language.

Meanwhile, according to Lukman (2000), the shifting of a language, whether in the minority or majority group of immigrants/migrants, is influenced by many factors, among them are the loyalty factor, the concentration of residential areas, and keep using language in the realm of traditional every day.

\subsection{Language Shift}

The shift of language always refers to the situation of language contact, where the minority groups leave their language slowly, and have to use another language regularly. Furthermore, due to language shift, one of the code loses its speakers while others gained more speakers (see Dorian, 1981; Fishman, 1991; Fasold, 1992; Romaine, 1995). In other words, the language that has been used as a means of communication and socialization is taken over by other languages so that there is a decrease or reduction in the realm of language use (Batibo, 2005). 


\section{International Journal of Science and Research (IJSR) \\ ISSN (Online): 2319-7064 \\ Index Copernicus Value (2013): 6.14 | Impact Factor (2014): 5.611}

Studies on the preservation of language and language shift related to the change and stability in the habit of language use on the one hand, and the psychological, social and cultural constantly on the other hand, when the populations of different languages are related to each other (Fishman, 1964).

Language shift occurs when people said a language using the new language replacing the previous language more prestigious. Conversely, retention of language occurs when society collectively he said still maintaining the pattern of use of language.

Furthermore, Hoffman (1991) states that the language shift occurs when a society does not maintain its language but gradually adopt other languages. From the viewpoint of a somewhat different, Weinreich (1968) said that the language shift is the habit of using one language than any other language.

More specifically, Anderson (2010) stated that the language shift can be known through four communication situations most decisive in terms of how children learn the local language of the parents, namely (1) parents talk to their children at home, (2) the child speaks to his parents at home, (3) a child play outside and (4) a husband and wife talk to each other at home. Bertemali the realm of language use in the home, Romaine (1995) argues that language shift is inevitable when two languages compete in the same realm.

Bilingualism may eventually lead to a shift of language in society and are often characterized by the transition intergenerational language as stated by Fasold (1984), Aitchison (1981), and Fishman (1991) following.

"Ultimately Bilingualism can lead to a language shift in a society and is Often marked by intergenerational switching of the languages."

Furthermore, Fishman added that the language shift occurs particularly in the speech community whose native language is endangered due to negative intergenerational sustainability, i.e. with less and less users of these languages in every generation that will have an impact on future generations. Furthermore, according to Fishman, language shift usually occurs in the third generation. The use of language in various domains is an indicator that the language shift is underway. In addition, Edwards (1947) says that one of the phenomena that lead to a shift in language is the reduced number of young speakers of the language because they tend to use other languages are considered more prestigious.

Based on the various definitions suggested by experts above, the shift of language can be summed up as the changing habits of speech community to use native language to the language used widely considered more prestigious, reflected by the behavior of their language. The repertoire of this language began to be used in various domains through the use of negative intergenerational transmission in the family.

Research on language shift can be divided into three types, namely research concerning real change in the pattern of language use was pioneered by Joshua Fishman. This study assumes that the language used in the realm of high prestige will naturally replace the language used in the realm of lesser prestige. The second type of research that focuses on the language selection correlation with social factors, such as the number of speakers and geographical spread of language, the language studied whether it has the written culture or not, whether the dominant group in a variety of ways suppress minorities or not. This thinking was pioneered by Heinz Kloss. The third type is the model introduced by Einar Haugen by looking at the interaction with the speakers of the language and its people. This type of research is then developed by Giles (1977), which highlights the vitality of ethno linguistic minority languages based on status, demographic and institutional support. Edwards (1992) conducted a similar study on the typology of languages threatened with extinction.

\subsection{Influence Factors of Language Shift}

A language survive or become extinct is not determined by a single factor as said by Dorian in Sumarsono (2004), but a lot of factors that are a chain of mutually adrift and occasionally occurred in the long history. These factors can be sourced from within the community itself or from outside. Similarly Grimes (2002) outlines the factors of language shift among others caused by (1) parents who force their children to learn a language that is considered prestigious by the idea that a child is only able to learn a language well, (2) the use of a second language as the language of instruction in schools, (3) a national language policy that is likely to cause some speakers choose to use the national language which is likely to cause some speakers choose to use the national language as a mother tongue and (4) industrialization, economic change, and governance.

The loss of a language is lost anyway imply ethno cultural identity (Fishman, 2001). It is said that people living in urban areas are more likely to lead to a shift in the language. Meanwhile, Fasold (1984) said that the language shift can cause these languages are endangered and even extinct. Similar opinions were expressed by Dorian (1982) that the language was abandoned by its speakers gradually resulted in the death of a language.

Relating to the language shift, Holmes (1994) says that the factors that can cause a shift in language are a factor of social, economic, political and demographic. Grimes (2002) provide reasons in more detail that the factors that led to a shift in language are: (1) parents are too forcing children to learn the language prestigious on the assumption that children are only able to learn a language well, a second language is considered more favorable from the point economic or education; (2) the use of a second language as a language of instruction that is widespread in the community; (3) a national language policy shift will cause a portion of the population using the national language.

According to Romaine (1995) factor of language shift can be the strength of the majority against minority groups, social class, religious background, education, relationship with the land of origin, the level of similarity between the language of the majority to the minority language, the attitude of the 


\section{International Journal of Science and Research (IJSR) \\ ISSN (Online): 2319-7064 \\ Index Copernicus Value (2013): 6.14 | Impact Factor (2014): 5.611}

majority towards the minority, intermarriage, government policies on language education and minority groups, as well as the patterns of language use.

Grosjean (1982) classifies the factors of language shift into five factors, namely social, attitude, language usage, government policy, and other factors. Meanwhile Sasse (1992) divides the aspects that are relevant to language shift into three groups, namely: (1) factors extra linguistic (external setting) which includes culture, sociology, ethno historic, economic, political, and social; (2) says that the behavior sociolinguistic factors, including the use of languages in a multilingual situation, use a different style of language and attitudes towards language variation; (3) consequences that changes occur in the structure of the language itself, both at the level of phonology, morphology, syntax, and lexicon. Of the aspects mentioned above, language threat occurs exclusively on extra linguistic factors (see Sasse, 1992; Tsunoda, 2005). Based on these explanations, then aspects of language threat can be described as follows:

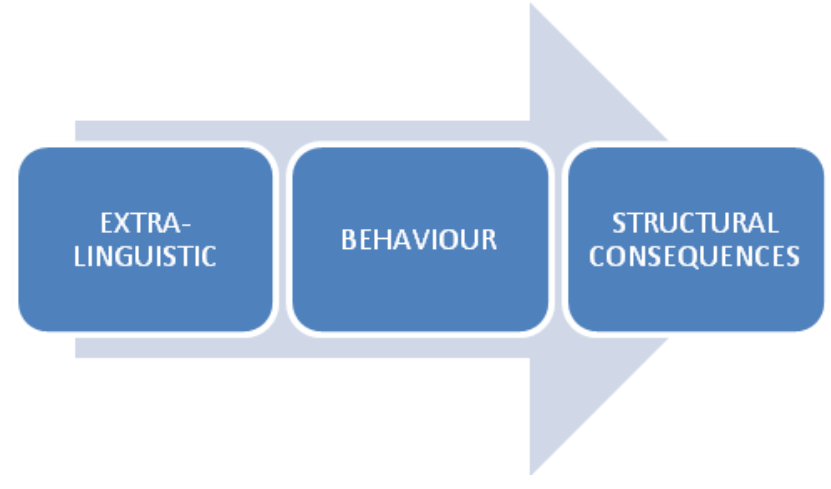

Furthermore, with regard to the rate of language shift, then the death of a language can be classified as (1) a sudden glottocide, (2) gradual glottocide, (3) language sudden shift and (4) gradual language shift. The first group occurs when speakers are no longer due to sudden death. This case is very rare. The second group occurs when a population of speakers of this language group is reduced gradually until the last member of this group is the last speakers. Cases like this are rare. The third group occurs when populations shift language to another language suddenly. The fourth group happens when language shift that happens slowly. It seems from these four groups, a shift in Ternate language included in the category of this latter group.

Fast or slow a language shift or dying can be assumed with ten years as a long time, and five years as a fast time. Five years categorized as a fast time for the shifting of a language because in this period of time the children need to obtain language.

\section{Method}

The study used the mixed method research design, where data is collected through a survey using questionnaires, interviews and observation. This method is used with the assumption that the problems will be more complete and better penelitian questions (Creswell, 1994).
This study examined data obtained by describing the relationship between variables and explain the meaning of the data processed.

This study was conducted from December 2014 - May 2015 in areas of concentrated native speakers, namely district of Central Ternate, district of North Ternate, and district of Ternate island were determined purposively.

To measure the rate of language shift, questions focused on the four most crucial communication situations in terms of language acquisition children from parents. These questions include what language is used by: 1) parents and children at home; 2) children with children at home; 3) a husband and wife at home; and 4) children and friends around the house.

The data analysis technique used to measure the rate of the shift is simple analysis technique by using Microsoft Office Excel. All data questionnaire related to the rate of Ternate language shift Ternate were gathered based residential areas are villages and towns, and then calculated the average of the language use of Respondents.

As for the view and determine the magnitude of the influence of the level of education, work, attitude, language, culture and language skills (bilingualism) to the language shift in Kota Ternate, quantitative data were processed using SPSS Ver. 16.

\section{Result and Discussion}

The regression equation is used to analyze the factors that cause a shift of TTL either jointly or partially.

F test is used to determine whether simultaneously the independent variables are able to explain the dependent variable properly or whether the independent variables have a significant effect toward the dependent variable.

On the table Analysis of Variance (ANOVA), it can be seen the influence of independent variables: education level (x1); jobs (x2); Proficiency (bilingual) (x3); language attitudes (x4); and culture (x5) toward the shift of TTL as dependent variable (y) simultaneously.

Simultaneous significance test (statistical $f$ test) of the result produces 1.353 of an $f$ counted value, while the value of $f$ tables at the 0.05 confidence level is 1.001 . Thus $f$ counted value is higher than $f$ table value or $1.353>1.001$ with a significance level $0.025(\mathrm{p}<0.05)$. Therefore, it can be stated that that the independent variables: education level (x1); jobs (x2); Proficiency (bilingual) (x3); language attitudes (x4); and culture (x5) jointly or simultaneously affect the dependent variable (y), shift of TTL.

The magnitude of the effect of independent variables toward the shift of TTL can be seen from the calculation results of Summary model, especially the value of Adjusted R Square with the amount of value is 0.680 . This value means that the percentage of influence exerted by the independent variable (x) toward the shift of TTL (y) is equal to $68 \%$, while the remaining $32 \%$ is influenced by other variables which are not included in this study. 


\section{International Journal of Science and Research (IJSR) \\ ISSN (Online): 2319-7064 \\ Index Copernicus Value (2013): 6.14 | Impact Factor (2014): 5.611}

Statistically $\mathrm{T}$ test is basically used to observe the effect of independent variables toward the dependent variable partially. Where in this study to see the effect of independent variables: education level (x1); jobs (x2); Proficiency (bilingual) (x3); language attitudes (x4); and culture (x5) to shift TTL dependent variable (y) partially or individually.

The results of the hypothesis by using $t$-test or partial test, it is known to the Sig. $t$ for each independent variable educational level $(\mathrm{x} 1)=0.047<0.05(\mathrm{p}<0.05)$, employment $(\mathrm{x} 2)=0.003<0.05(\mathrm{p}<0.05)$, bilingual $(\mathrm{x} 3)=0,027<0,05$ $(\mathrm{p}<0.05)$, and the attitude of the language $(\mathrm{x} 4)=0.33<0.05$ $(\mathrm{p}<0.05)$. It can be concluded that the education level $(\mathrm{x} 1)$; jobs (x2); bilingual (x3); and the attitude of the language (x4); significant effect on the shift TTL, which of the four variables, the variable job has the highest influence is $59.32 \%$, then the ability to speak (bilingual) $44.10 \%$, $40.86 \%$ attitude and final language education level $40.07 \%$.

Meanwhile to the results of the hypothesis by using $t$-test or partial test, it is known that Sig.t value for cultural variables $(x 5)=0323<0.05(p<0.05)$. It can be concluded that the cultural variables (x5) no significant effect on TTL shift.

TTL as a communication tool for the native Ternate speakers began experiencing fading, for example in teenagers. The more teenagers use a mix of languages that come from other cultures. Teens in the city of Ternate and its surroundings, due to several factors, are contaminated with another language.

Community employment relationship of language to the language they use in everyday life is almost the same as the language shift relationship with the level of education.

If TTL speakers work in the social context dominated by the language itself, their native language will last long. However, if they work in a heterogeneous social context, the level of interference of the TTL with the other languages will intensify. The result will be a shift and change of the language, so unconsciously it will happen to the penetration of other language elements into TTL.

The job factor is one of acceleration triggers of the shift of TTL. This is due to the work environment is a heterogeneous social context in the use of language. TTL is not the only language used, so if they are not aware, they would be affected in adopting the language elements that are always used in their work environment. Gradually, such conditions may result in a shift of the elements of TTL.

In addition, one economic factor is the existence of industrialization which is much acted by entrepreneurs. Economic progress sometimes elevate the position of a language into a language that has a high economic value. English for instance, became the interest of many people to master and if necessary leave the first language. The more advanced of economies, people are required to be able to master several languages needed in industrialization especially English. It eventually became a benchmark or the main requirement in a job. English will shift TTL and INL as a first language.
Language is one of the elements of culture but it is also a communication tool that allows people to be able to perform mutual social interaction. Language has several social functions i.e. social communication, social control, and social cooperation. The function of language in communication is to send a message. TTL and TML as well as the communication interface devices.

Language used as characteristic or identity by the community, and also as a means of social interaction when communicating with anyone and anywhere. Language can be a means of assessing the patterns of behavior.

Based on the result of the analysis of native Ternate speakers' attitude to TTL, the average respondents are negative in both rural and urban regions. This causes the use of TTL in different situations and places greatly reduced, since the young generations tend to use TML and INL in their daily interaction. This negative attitude contributes to the shift of TTL.

Language is one of the elements of culture, but it is also as a means of communication in social interaction. Language has several social functions i.e. social communication, social control, and social cooperation. Both languages are interface devices which are used interchangeably.

Based on the research conducted, it was found that the culture does not contribute significantly to the shift of TTL. This is due to TTL still retained used in cultural ceremonies in Ternate. So the TTL is not yet shifted if the speakers use the TTL in the ritual situation.

\section{Conclusion}

The shift of language occurs when the mother tongue began to be abandoned by the native speakers and collectively to use another language. This phenomenon always preceded by bilingualism as a result of the contact language. Hoffman (1991) says that if a community does not retain their language, but slowly adopting another language, then the language shift has occurred.

There are several factors that cause a shift of TTL. the external factors which include factors such as cultural factors, economics, history, marriage patterns, locality, sustainability and inter-generational transfer of the degree of similarity between languages. In addition to external factors, sociolinguistic and internal factors such as motivation, language behavior, language attitudes and language skills also contribute to language shift of Ternate. As a result there is a change in the structure of linguistic convergence resulting form a tendency to the shift of TTL.

The results this research shows that the job variable has the highest influence towards TTL shift, it is 59.32\%; then followed by bilingual, $44.10 \%$; attitude is $40.86 \%$; and level of education, $40.07 \%$. Meanwhile cultural variable does not significantly effects the shift of TTL. 


\section{International Journal of Science and Research (IJSR) \\ ISSN (Online): 2319-7064}

Index Copernicus Value (2013): 6.14 | Impact Factor (2014): 5.611

\section{Author Profile}

Farida Maricar is an English lecturer in Faculty of Letters and Culture from Khairun University, Ternate, Indonesia. She got her bachelor degree (Dra) in 1991 at Faculty of Letters from Hasanuddin University in Makassar, Indonesia and her magister degree (M.Hum) in 2007 at Postgraduate Program in Faculty of Cultural Studies from Gajah Mada University. Since 2010, she continued her study to get her doctorate degree on Linguistics at Hasanuddin University in Makassar, Indonesia. This paper is a part of her dissertation entitle 'Language Shift and Structural Change in Ternate Language: A Sociolinguistic Study' under the supervision of Prof. Dr. Lukman, MS (promotor), Prof. Dr. H.M. Darwis, M.S, and Prof. Dr. Tadjuddin Maknun, S.U. (Co-promotors). 